\title{
Cost-related unmet need for healthcare services in Kenya
}

Purity Njagi ${ }^{*}$, Jelena Arsenijevic ${ }^{2}$ and Wim Groot ${ }^{1,3}$

\begin{abstract}
Background: The assessment of unmet need is one way to gauge inequities in access to healthcare services. While there are multiple reasons for unmet need, financial barriers are a major reason particularly in low- and middleincome countries where healthcare systems do not offer financial protection. Moreover, accessibility and affordability are paramount in achieving universal health coverage. This study examines the extent of unmet need in Kenya due to financial barriers, the associated determinants, and the influence of regional variations.

Methods: We use data from the 2013 Kenya household health expenditure and utilization (KHHEUS) cross sectional survey. Self-reported unmet need due to lack of money and high costs of care is used to compute the outcome of interest. A multilevel regression model is employed to assess the determinants of cost-related unmet need, confounding for the effect of variations at the regional level.

Results: Cost-related barriers are the main cause of unmet need for outpatient and inpatient services, with wide variations across the counties. A positive association between county poverty rates and cost-related unmet is noted. Results reveal a higher intraclass correlation coefficient (ICC) of 0.359(35.9\%) for inpatient services relative to $0.091(9.1 \%)$ for outpatient services. Overall, differences between counties accounted for $9.4 \%$ (ICC 0.094) of the total variance in cost-related unmet need. Factors that positively influence cost-related unmet need include older household heads, inpatient services, and urban residence. Education of household head, good self-rated health, larger household size, insured households, and higher wealth quintiles are negatively associated with cost-related unmet need.

Conclusion: The findings underscore the important role of cost in enabling access to healthcare services. The county level is seen to have a significant influence on cost-related unmet need. The variations noted in cost-related unmet need across the counties signify the existence of wide disparities within and between counties. Scaling up of health financing mechanisms would fundamentally require a multi-layered approach with a focus on the relatively poor counties to address the variations in access. Further segmentation of the population for better targeting of health financing policies is paramount, to address equity in access for the most vulnerable and marginalized populations.
\end{abstract}

Keywords: Cost-related, Unmet need, Multilevel analysis, Healthcare, Equity

\footnotetext{
*Correspondence: p.njagi@student.maastrichtuniversity.nl;

puritynjagih@gmail.com

'United Nations University-MERIT, Maastricht Graduate School of Governance,

Maastricht University, Maastricht, The Netherlands

Full list of author information is available at the end of the article
}

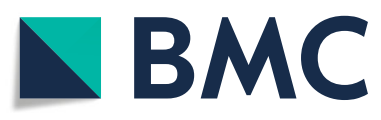

(c) The Author(s). 2020 Open Access This article is licensed under a Creative Commons Attribution 4.0 International License, which permits use, sharing, adaptation, distribution and reproduction in any medium or format, as long as you give appropriate credit to the original author(s) and the source, provide a link to the Creative Commons licence, and indicate if changes were made. The images or other third party material in this article are included in the article's Creative Commons licence, unless indicated otherwise in a credit line to the material. If material is not included in the article's Creative Commons licence and your intended use is not permitted by statutory regulation or exceeds the permitted use, you will need to obtain permission directly from the copyright holder. To view a copy of this licence, visit http://creativecommons.org/licenses/by/4.0/ The Creative Commons Public Domain Dedication waiver (http://creativecommons.org/publicdomain/zero/1.0/) applies to the data made available in this article, unless otherwise stated in a credit line to the data. 


\section{Introduction}

Delaying or forgoing treatment may have negative effects on health status among different population groups [1]. Furthermore, forgoing necessary treatment might impose a financial burden in the long run, or even lead to poorer health. At least half of the world's 7.3 billion population are reported to not receive the essential health services they need [2]. This is more profound in developing countries where many people go without health care from which they could benefit greatly [3]. The reasons for forgoing healthcare can be found in the numerous barriers that hinder access such as [4] financial, organizational, social, psychological or cultural barriers. These barriers may limit use of healthcare services and impose large healthcare coverage gaps among different population groups [5]. One method of gauging equity of access to services is through assessing unmet needs for health care [6, 7]. Unmet need is implicitly defined as the difference between the services judged necessary and the services actually received, resulting from barriers related to accessibility, availability and acceptability [8]. There are two recommended approaches for measuring unmet need. On the one hand, one can use a 'clinical' assessment based on relevant clinical guidelines. On the other hand, there is a 'subjective' measure based on the individual's own assessment not to have received healthcare when needed because of access barriers beyond their control [9]. The subjective measure is a widely used approach due to its feasibility as many surveys include self-reports by individuals on the time, they needed care but did not receive it $[10,11]$.

Poor functioning health financing systems and the cost of health services may deter people from seeking healthcare when they need it in order to avoid financial burden. This is especially observed when direct out of pocket (OOP) payment are involved [12, 13]. Financial access is thus critical, given that it can lead to catastrophic costs and/or impoverishment $[14,15]$. When there are no direct costs at the time of access to healthcare services (out of pocket patient payments (OOP) for example), then catastrophic health expenditure can be prevented [16]. Many studies have used catastrophic health expenditure to gauge the extent of financial protection. However, given $\mathrm{CHE}$ occurs in the form of direct and indirect health expenditure it is only incurred if sick individuals actually seek the needed healthcare. This means that the small incidence of $\mathrm{CHE}$ in some countries may create the impression of a greater degree of financial protection than what it provided by the system [15]. Furthermore, the analysis of CHE may suffer from selection bias. For instance a low incidence of catastrophic spending might simply reflect a situation in which only a few people get the health care they need [17], and we do not observe people who need care but are unable to get it.
In case of the Kenya health care system, inequities in accessing the healthcare services can be described as problems in regional discrepancies in the health service distribution, disparities in resource allocations, and inequitable access to quality health services [18, 19]. Significant regional inequities remain where northern counties, rural households and ethnic minorities are reported to have worse healthcare coverage [20]. Recent analysis show regional disparities in access, in that some regions are less likely to go without medical care, while other regions experience difficulty in obtaining medical care $[21,22]$.

The inequities in accessing healthcare services are also related to unmet need. A large variation in unmet healthcare needs is reported across counties ranging between 4.1 to $40.4 \%$, with the cost being one of the top reasons why people forgo care [23]. Furthermore the counties vary by socioeconomic composition, as some are pre-dominantly rural while others are urban [24]. Additionally, the numbers of those who do not seek care in Kenya due to costs is particularly high in the rural areas [25].

Studies on unmet need for care in Kenya and the region have primarily examined overall reasons for unmet need for specific health services, particularly reproductive services [26-30]. Others have focused on barriers to utilization of services such as non-availability of drugs, staffing inadequacy among others [31, 32]. To our knowledge, there has been no study that has looked at the factors influencing unmet need for healthcare due to costs alone. Analysis of the reasons for unmet need can be important in focusing policy actions [9]. This study adds to the existing literature on financial access by first, examining the extent of cost-related unmet need for healthcare and second, explaining how much of the cost-related unmet need is attributable to the differences in individual characteristics, and the effect of the variations at the regional (county) level. Geographical assessment of unmet need is critical in the Kenyan context given the recent (2013) decentralisation of the health care system to new sub-national governance units (counties). Moreover, the counties have the responsibility for healthcare financing and provision of services. This study applies a multi-level regression analysis model to provide for factors that are contextual at the individual/household level, adjusting for variations at the county level. Furthermore, many empirical studies are reported to focus on individual level and/or aggregate level inequities and not paying attention to multilevel structures [33]. A multilevel analysis provides a more nuanced understanding of the drivers that are influential at the different levels. Disaggregating unmet need discerns those reasons that are relevant to policymakers, and those reflecting individuals' and households' preferences and taste [34]. The findings 
of this study are relevant in informing the healthcare financial reforms in Kenya both at the national and at the county level, to better improve access to services to underserved populations, and hence accelerate achievement of universal health coverage (UHC) across all regions.

\section{Methods}

Data

This study uses data from the Kenya household health expenditure survey (KHHES) implemented by the Ministry of Health in collaboration with Kenya National bureau of statistic every 5 years. This is a national representative household survey aimed at collecting data on household health care utilization. The survey collects data on individuals who were ill, those who sought care, and the reasons for not seeking care when ill. Other data collected include demographic and socioeconomic characteristics of the individuals and households. This study utilizes data from the 2013 survey which covered Kenya's 44 out of the 47 counties. A total of 33,675 households (152,566 individuals) were interviewed from 1347 selected clusters; 814 (60\%) were rural and $533(40 \%)$ urban clusters with a response rate of $87.7 \%$.

\section{Variables}

\section{Outcome variable}

Unmet need for healthcare is seen to cover a spectrum of healthcare needs that are not optimally met. On one hand is "unexpressed demand" referring to people with healthcare needs who are not aware of them, or who do not to seek healthcare. On the other hand is "expressed demand" referring to healthcare needs that are suboptimally met [35].

This study uses a dependent (outcome) variable related to "unexpressed demand", which is the subjective perception of not receiving appropriate care when needed [36]. We look at whether people with healthcare needs choose not to seek care due to the high cost of care and lack of money, referred to as self-reported 'cost-related unmet need' for healthcare services. We construct the cost-related unmet need for healthcare variable from two sets of questions:

(i) Outpatient - Was <NAME $>$ ill in the last 4 weeks? If Yes, ...... did $<$ name $>$ visit/consult a health provider?

(ii) Inpatient - Did [Name] need to be admitted in a hospital in the last 12 months? If Yes ......, was < name> admitted?

The reasons why healthcare was not sought when needed are derived from two closed ended questions framed as follows; Outpatient - "If No ......, what was < name>'s main reasons for not seeking care?" and
Inpatient "If No ......., why was <name> not admitted?". The responses are a pre-defined set of multiple-choice categories allowing for multiple responses. They include; lacked money, prescribed drugs were not available, selfmedication, poor quality of service, high cost of care, religious/cultural issues, fear of discovering serious illness, long distance to the provider and illness not considered serious enough.

\section{Explanatory variables}

Based on Andersen's Health Behaviour Model we distinguish three groups of factors that affect access to healthcare services: need, predisposing and enabling factors $[37,38]$. We thus classify the independent variables into (i) predisposing factors such as: age of household head, gender of household head, education level of household head and employment status of household head, (ii) need factors such as: type of service sought (inpatient/ outpatient care), self-rated health status and chronic illness, and (iii) enabling factors such as: household wealth, household size, insurance status, and residence (rural/ urban).

\section{Analysis}

This study applies a multilevel logistic regression model to analyse the association and variability between costrelated unmet need for care, and the independent factors. Multilevel analysis is preferred given that it allows for the simultaneous examination of the effects of group-level and individual-level factors and groups are perceived as related, that is coming from a larger population of groups [39]. Additionally, multilevel analysis accounts for dependencies of observations within groups [40]. Multilevel (logistic) regression disentangles the within-cluster effects from the between-cluster effects [41]. Relative to conventional models, multilevel models provide a more accurate and comprehensive description of relationships in clustered data [42]. In this study, individuals and households are nested within regions known as counties, thus we use counties as the group level variable. First, we present the proportion of people who face unmet need and the different reasons for unmet needs (see Table 1), then we present descriptive statistics for unmet need related to costs (see Fig. 1 and Fig. 2), and the results related to logistic multilevel regression (see Table 3). We fit a Pearson's correlation coefficient test statistic to assess the association between poverty rates, and cost-related unmet need for healthcare services. A $\log$ likelihood ratio test is used to assess the goodness of fit between the general logistic model and the multilevel model. Additionally, this study applies two commonly used information criteria - Alkaike's information Criterion(AIC) and the Bayesian Information Criterion (BIC), to assess the relative model goodness of fit [43]. 
Table 1 Unmet need for healthcare services and the reasons for unmet need

\begin{tabular}{|c|c|c|c|c|c|c|}
\hline \multirow[t]{2}{*}{ Variables } & \multicolumn{2}{|c|}{ Outpatient } & \multicolumn{2}{|c|}{ Inpatient } & \multicolumn{2}{|l|}{ Total } \\
\hline & $\mathrm{N}$ & $\%$ & $\mathrm{~N}$ & $\%$ & $\mathrm{~N}$ & $\%$ \\
\hline Was ill and Needed admission & 36,901 & 88.3 & 4882 & 11.7 & 41,783 & \\
\hline Did not seek healthcare services & 3009 & 86.9 & 453 & 13.1 & 3462 & \\
\hline Percentage with unmet need & & 8.2 & & 9.3 & & 8.3 \\
\hline Percentage with cost-related unmet need & & 2.9 & & 5.2 & & 3.2 \\
\hline \multicolumn{7}{|l|}{ Reasons for unmet need } \\
\hline Cost-related (Lack of money and high costs) & 1081 & 35.9 & 256 & 56.5 & 1337 & 38.6 \\
\hline Illness was not considered serious & 1070 & 35.6 & 88 & 19.4 & 1158 & 33.5 \\
\hline Self-Medication & 646 & 21.5 & 32 & 7.1 & 678 & 19.6 \\
\hline Long distance to the health provider & 49 & 1.6 & 8 & 1.8 & 57 & 1.7 \\
\hline Religious/cultural reasons & 36 & 1.2 & 5 & 1.1 & 41 & 1.2 \\
\hline Fear of serious illness & 11 & 0.4 & 1 & 0.2 & 12 & 0.4 \\
\hline Perceived poor quality of service & 8 & 0.3 & 4 & 0.9 & 12 & 0.4 \\
\hline Perceived lack of drugs at the facilities & 10 & 0.3 & 4 & 0.9 & 14 & 0.4 \\
\hline Other reasons (Not specified) & 98 & 3.3 & 55 & 12.1 & 153 & 4.4 \\
\hline Total (N) & 3009 & & 453 & & 3462 & \\
\hline
\end{tabular}

\section{Results}

Proportion of population with unmet need for healthcare services

The analyses show that out of those who needed health care services $88.3 \%$ needed outpatient services within the last 4 weeks, whereas $11.7 \%$ needed inpatient services within the last 12 months. However, $8.3 \%$ did not seek the needed healthcare services. Unmet need for healthcare services was higher among those that needed inpatient services at $9.3 \%$, relative to those that needed outpatient services at $8.2 \%$. Table 1 shows the proportion with unmet need, and the various reasons for unmet need for healthcare services. The top reasons why people had to forgo care were cost-related (38.6\%), Illness not

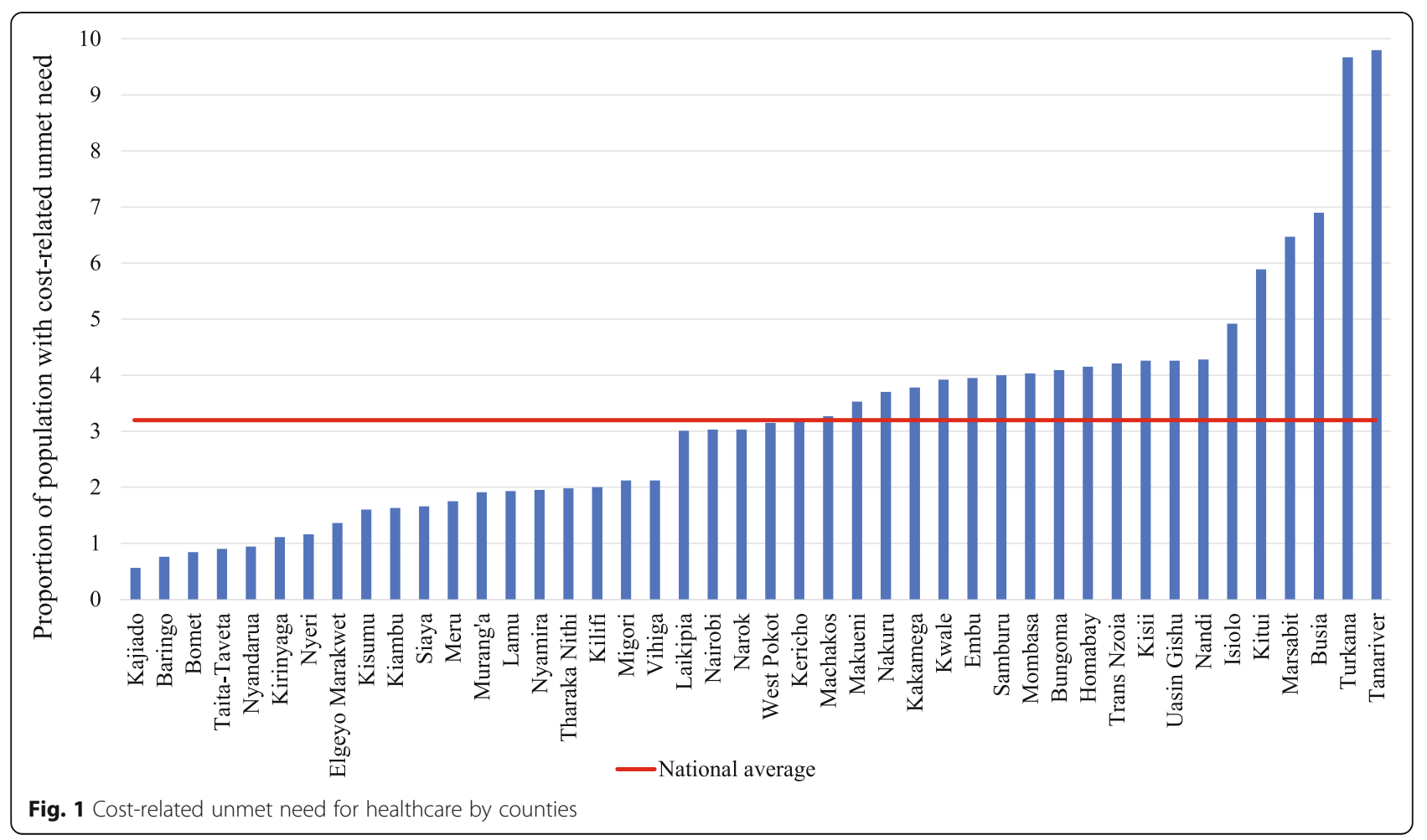




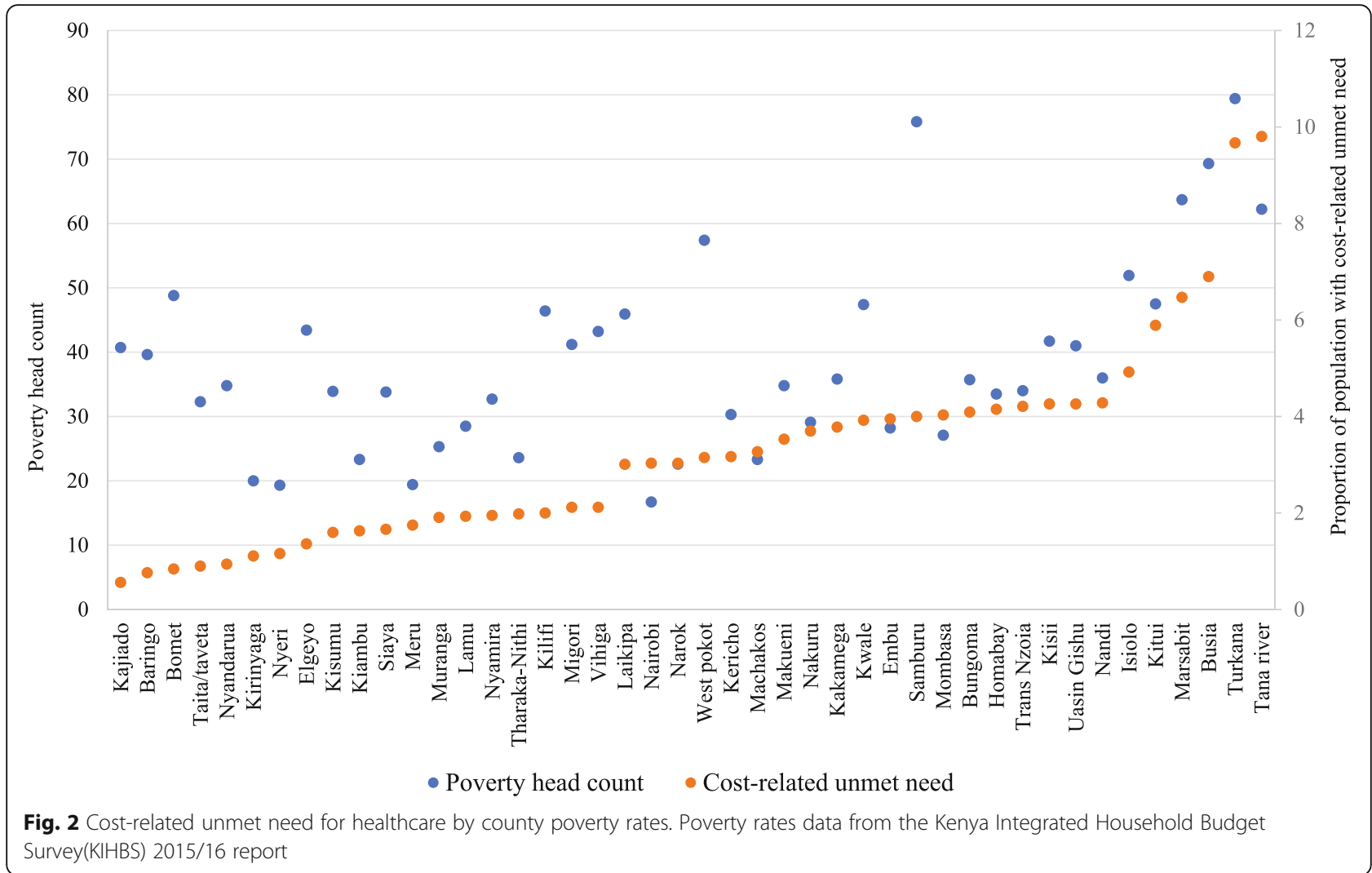

considered serious (33.5\%), and self-medication (19.6\%). Cost-related reason was higher for inpatient services (56.5\%) compared to outpatient services (35.5\%).

Of those who needed outpatient or inpatient services, $3.2 \%$ did not seek the needed healthcare services due to cost, that is high cost of the services and/or lacked the money. Our analysis show that cost-related unmet need is higher for inpatient services at 5.2\% compared to the outpatient services at $2.9 \%$. Additional file 1 further presents the distribution across counties of those that did not seek healthcare services due to cost-related reasons, and other reasons including no drugs, self-medication, poor quality service, religious/cultural reasons, fear that the illness is serious, distance to provider and illness not considered serious.

Figure 1 shows the distribution of those who experienced cost-related unmet need by counties. The analysis shows a wide variation in cost-related unmet need among the counties from $<1$ to $9.8 \%$. Nearly half $(43 \%)$ of the counties had cost-related unmet need higher than the national average of $3.2 \%$. We observed that several counties with a prevalence of unmet need of $<1 \%$, had small samples $(\mathrm{N})$ of up to $<10$ persons with cost-related unmet need (See Additional file 1). In light of this, we run a sensitivity analysis on the multilevel model to assess the robustness of the findings without the 9 counties that have a cost-related unmet need of less than $10 \%$.

\section{Descriptive analysis of the population with cost-related} unmet need for healthcare

The distribution of those who experienced cost-related unmet need for healthcare by the socio-economic characteristics is presented in Additional file 2. Households head above 40 years accounted for the majority of those who had cost-related unmet need (64.3\%). The majority (81.1\%) of those who experienced cost-related unmet need came from households with a head with primary education only. Persons with cost-related unmet need from male headed households were $68.1 \%$, similarly $82.5 \%$ with cost-related unmet need had an employed (formally and informally) household head. More than half (56.3\%) of those with cost-related unmet need selfrated their health as good. Only $26.2 \%$ of those with cost-related unmet need had chronic illness. Cost related unmet need for care was experienced by 42.3 and $31.7 \%$ of the people from medium and large size $(7+)$ households respectively. Only $7.3 \%$ of those who experience cost related unmet need for care were from insured households. Rural households accounted for majority $(70.3 \%)$ of the individuals who experienced cost-related unmet need for healthcare. Of the individuals who experienced cost-related unmet need for care, the majority were from poorest households (38.1\%), while the least were from among the richest households (4.8\%). 
There was a statistically significant positive correlation (Pearson's r 0.638; $p$-value $<0.0001$ ) between the country poverty rates, and cost-related unmet need for healthcare. The majority of the counties that experienced high cost-related unmet need for healthcare had high poverty rates as shown in Fig. 2.

\section{Multilevel analysis of cost-related unmet need for healthcare}

We fit both the general logistic regression model, and the multilevel regression model (see Additional file 3). Although the estimates from both models show small differences, the log likelihood test confirms that there is a statistically significant difference between the two models $\left(\mathrm{chi}^{2}=257.14, P\right.$-value $\left.<0.001\right)$. Relative to the logistic regression model, the multilevel model has the lowest AIC and BIC, indicating it is the better fitting model as illustrated in Table 2. This demonstrates that controlling for the county level variation leads to a significant improvement of the model, relative to running a general regression model. We therefore discuss the results from the multilevel model which controls for between counties' variation.

Table 3 presents the analysis from the multilevel logistic regression models. We fit three models including an outpatient model 1 , an inpatient model 2, and an overall model 3 controlling for outpatient and inpatient services. The results show the association of the predisposing, need and enabling factors on cost-related unmet need for healthcare services at the individual level confounding for the county level. Overall, the results show an estimated intraclass correlation coefficient (ICC) of 0.094, meaning that $9.4 \%$ of the variance in cost-related unmet need is attributable to county level variations. This is close to the 0.091 ICC reported in the outpatient model, indicating the county level accounted for $9.1 \%$ of the variation in outpatient cost-related unmet need. Equally, we note a higher ICC of 0.359 in the inpatient model, suggesting that county level variation accounts for $35.9 \%$ of the inpatient cost-related unmet need. Given that 9 counties had a very low sample $(<10)$ with cost-related unmet need, a separate multilevel model is fitted without these counties to assess the robustness of the findings. The intraclass correlation coefficient(ICC) is $6 \%$ relative to $9.4 \%$ in the multilevel model with all the counties. Additionally, the direction of the effect of the explanatory factors on cost-related unmet need is the same in both models. Furthermore, the confidence intervals for all the factors are overlapping meaning there is no significant difference between the two models. Finally, we run a log-likelihood ratio test which indicates no statistically significant difference between the two models.

The analysis shows a positive association between cost-related unmet need for health care and older household heads ( +40 years) in both the outpatient and overall model. Relative to households with younger heads (below 25 years), older households have 79 and 92\% higher odds of unmet need for healthcare due to cost in the overall and outpatient model respectively. In addition, household heads with tertiary education have 47 and 52\% lower odds of cost-related unmet need for healthcare relative to those with no education in the overall and outpatient model respectively. Although in the inpatient model being an employed households' head was associated with 33\% lower odds of experiencing cost-related unmet need, in the outpatient and overall model, employment status of the household head had no significant association with cost-related unmet need.

The overall model shows seeking inpatient services was associated with $95 \%$ increase in the odds of costrelated unmet need. There was a negative association between good self-rated health and cost-related unmet need across the three models, with $44 \%$ reduced odds of unmet need for care due to costs in the overall model relative to poor self-rated health. Insured households were $50 \%$ less likely to have cost-related unmet relative to uninsured households, meaning the odds were even in the overall model. Household size was negatively associated with cost-related unmet need for care across the three models. For instance, medium and larger households had 31 and 29\% lower odds of cost-related unmet need respectively, relative to those from small households.

Urban residents were $25 \%$ in the overall model and $28 \%$ in the outpatient model, more likely to have costrelated unmet need for care relative to their rural counterparts. However, there was no association between cost-related unmet need and residence in the inpatient model. In all the three models, wealth status of the household was negatively associated with the costrelated unmet need for healthcare with the likelihood reducing as you move up the wealth quintiles. In the overall model, households in the richest quintile were $69 \%$ less likely to have unmet needs, while for the, fourth quintile this was $53 \%$, the middle quintile had a $37 \%$, and second quintile had $15 \%$ less chance to have cost-

Table $2 \mathrm{AIC}$ and BIC for the logistic and multilevel model

\begin{tabular}{lllllll}
\hline & Obs & II (null) & II (model) & df & AIC & BIC \\
\hline Logistic Model & 41,646 & -5889.088 & -5554.914 & 20 & $11,149.83$ & $11,322.57$ \\
Multilevel Model & 41,646 & - & -5426.346 & 21 & $10,894.69$ & $11,076.07$ \\
\hline
\end{tabular}


Table 3 Multilevel regression models for cost-related unmet need for healthcare

\begin{tabular}{|c|c|c|c|c|c|c|c|}
\hline \multirow[t]{2}{*}{ Factors } & \multirow[t]{2}{*}{ Categories } & \multicolumn{2}{|c|}{ Model 1: Outpatient } & \multicolumn{2}{|c|}{ Model 2: Inpatient } & \multicolumn{2}{|c|}{ Model 3: Overall } \\
\hline & & OR & {$[95 \% \mathrm{Cl}]$} & OR & {$[95 \% \mathrm{Cl}]$} & OR & {$[95 \% \mathrm{Cl}]$} \\
\hline \multicolumn{8}{|l|}{ Predisposing factors } \\
\hline \multirow[t]{2}{*}{ Gender } & Male $[\mathrm{RC}]$ & & & & & & \\
\hline & Female & 1.015 & $(0.88-1.17)$ & 1.115 & $(0.82-1.52)$ & 1.019 & $(0.89-1.16)$ \\
\hline \multirow[t]{3}{*}{ Age group $\mathrm{HH}$} & Below 25 years [RC] & & & & & & \\
\hline & $25-40$ years & 1.260 & $(0.85-1.87)$ & 1.452 & $(0.62-3.39)$ & 1.332 & $(0.94-1.89)$ \\
\hline & $40+$ years & $1.926^{* * *}$ & $(1.31-2.84)$ & 1.175 & $(0.50-2.76)$ & $1.793^{* *}$ & $(1.26-2.55)$ \\
\hline \multirow[t]{4}{*}{ Education level of $\mathrm{HH}$ head } & None $[R C]$ & & & & & & \\
\hline & Primary & 1.057 & $(0.66-1.69)$ & 0.364 & $(0.11-1.21)$ & 0.956 & $(0.62-1.46)$ \\
\hline & Secondary & 0.772 & $(0.47-1.27)$ & $0.229^{* *}$ & $(0.06-0.79)$ & 0.669 & $(0.43-1.05)$ \\
\hline & Tertiary & $0.488^{* *}$ & $(0.26-0.91)$ & 0.340 & $(0.08-1.31)$ & $0.534^{*}$ & $(0.31-0.92)$ \\
\hline \multirow[t]{2}{*}{ Employment status } & Not employed [RC] & & & & & & \\
\hline & Employed & 1.009 & $(0.83-1.22)$ & $0.668^{* *}$ & $(0.45-0.98)$ & 0.931 & $(0.79-1.10)$ \\
\hline \multicolumn{8}{|l|}{ Need Factors } \\
\hline \multirow[t]{2}{*}{ Type of service } & Outpatient [RC] & & & & & & \\
\hline & Inpatient & NA & & NA & & $1.950^{* * *}$ & $(1.68-2.26)$ \\
\hline \multirow[t]{3}{*}{ Self-rated health } & Poor $[R C]$ & & & & & & \\
\hline & Satisfactory & 1.108 & $(0.89-1.37)$ & $0.613^{* *}$ & $(0.41-0.92)$ & 0.942 & $(0.79-1.13)$ \\
\hline & Good & $0.661^{* * *}$ & $(0.54-0.81)$ & $0.348^{* * *}$ & $(0.24-0.51)$ & $0.567^{* * *}$ & $(0.48-0.67)$ \\
\hline \multirow[t]{2}{*}{ Chronic Illness } & No Chronic Illness [RC] & & & & & & \\
\hline & Chronic illness & 1.163 & $(0.99-1.37)$ & 0.822 & $(0.59-1.15)$ & 1.067 & $(0.92-1.23)$ \\
\hline \multicolumn{8}{|l|}{ Enabling factors } \\
\hline \multirow[t]{2}{*}{ Insurance status } & Not insured [RC] & & & & & & \\
\hline & Insured & $0.562^{* * *}$ & $(0.43-0.74)$ & $0.346^{* * *}$ & $(0.22-0.55)$ & $0.505^{* * *}$ & $(0.40-0.64)$ \\
\hline \multirow[t]{3}{*}{ Household size } & 1-3 Small [RC] & & & & & & \\
\hline & 4-6 Medium & $0.698^{* * *}$ & $(0.59-0.82)$ & $0.677^{* *}$ & $(0.46-0.99)$ & $0.693^{* * *}$ & $(0.60-0.80)$ \\
\hline & 7+ Large & $0.647^{* * *}$ & $(0.54-0.77)$ & 1.192 & $(0.80-1.77)$ & $0.717^{* * *}$ & $(0.61-0.84)$ \\
\hline \multirow[t]{2}{*}{ Residence } & Rural [RC] & & & & & & \\
\hline & Urban & $1.280^{* *}$ & $(1.10-1.49)$ & 1.358 & $(0.95-1.94)$ & $1.259^{* *}$ & $(1.09-1.45)$ \\
\hline \multirow[t]{6}{*}{ Wealth Index } & Poorest [RC] & & & & & & \\
\hline & Second & $0.826^{*}$ & $(0.69-0.98)$ & 0.921 & $(0.63-1.30)$ & $0.845^{*}$ & $(0.72-0.99)$ \\
\hline & Middle & $0.643^{* * *}$ & $(0.53-0.78)$ & $0.558^{* *}$ & $(0.36-0.86)$ & $0.632^{* * *}$ & $(0.53-0.75)$ \\
\hline & Fourth & $0.438^{* * *}$ & $(0.34-0.56)$ & $0.532^{* *}$ & $(0.33-0.85)$ & $0.470^{* * *}$ & $(0.38-0.58)$ \\
\hline & Richest & $0.371^{* * *}$ & $(0.26-0.53)$ & $0.131^{* * *}$ & $(0.05-0.32)$ & $0.314^{* * *}$ & $(0.23-0.44)$ \\
\hline & _cons & $0.040^{* * *}$ & $(0.02-0.08)$ & 0.372 & $(0.08-1.75)$ & $0.055^{* * *}$ & $(0.03-0.10)$ \\
\hline \multirow[t]{7}{*}{ Random effects } & /Insig2u [County variance] & -1.113 & $(-1.62--0.61)$ & 0.613 & $(-0.01-1.24)$ & -1.074 & $(-1.57--0.57)$ \\
\hline & sigma_u [Residual variance] & 0.573 & $(0.45-0.74)$ & 1.359 & $(0.99-1.85)$ & 0.585 & $(0.45-0.75)$ \\
\hline & Rho [Intraclass correlation (ICC)] & 0.091 & $(0.06-0.14)$ & 0.359 & $(0.23-0.51)$ & 0.094 & $(0.06-0.15)$ \\
\hline & Log likelihood & & -4513.35 & & -818.16 & & -5426.35 \\
\hline & Wald chi2(18) & & 354.35 & & 129.25 & & 443.84 \\
\hline & No. of observations & & 36,783 & & 4863 & & 41,646 \\
\hline & No. of groups & & 44 & & 44 & & 44 \\
\hline
\end{tabular}


related unmet need for healthcare relative to the those in the poorest quintile.

\section{Discussion}

The findings show that $8.3 \%$ of those who needed outpatient care or inpatient care did not seek healthcare services with inpatient unmet need being higher relative to outpatient unmet need. This is lower than the percentage for unmet need $-12.7 \%$ reported in the national report [23], given this study computed unmet need based on persons who provided a reason for not seeking outpatient or inpatient care. This means there are persons who did not provide any reason why they did not seek care when needed. Additionally, the national report highlights high cost among the top three most important reasons for not seeking care at $21.4 \%$ [23]. Our results emphasize cost as the major reason for not seeking healthcare at $38.6 \%$. This is in accordance with other studies in Kenya, and elsewhere that highlight cost as an important and most frequent reason for unmet need for care $[25,44-46]$.

The findings slightly differ from those of the national report because we define cost-related unmet need as a combination of two reasons "lacked money" and "high costs of care", whereas the national report focused on only the high cost of care. The lack of money could infer to other indirect costs of the service such as, transport costs like in rural areas where travel distances to the health facilities are longer $[3,47]$.

Overall, of those who needed outpatient or inpatient services, 3.2\% had to forgo the healthcare services due to cost-related issues (lack of money and high costs). We observe a higher cost-related unmet need for inpatient services relative to outpatient services. This could be because inpatient care is reported to be unaffordable to poor households because it is more costly than outpatient services [48].

Cost-related unmet need varies across the regions/ counties ranging from 0.56 to $9.8 \%$. However, $43 \%$ of the 44 counties $(n=19)$ do report cost-related unmet need higher than the average in the whole country. This is consistent with other studies in Kenya that have highlighted that health outcomes remain heterogeneous at the county level, although with convergence across counties overtime [49]. This means that cost-related unmet need might impose inequities in access to healthcare between counties. This could be also due to variation in socio-economic status across the counties. Our analysis also shows a positive association between the poverty rates of the counties, and cost-related unmet need for healthcare services. Consistent with other studies, results indicate that counties with high poverty rates had high cost-related unmet need, signifying that health costs are much more a burden to the poor [50].
We assessed the predisposing, need and enabling factors that are associated with cost-related unmet need for care through both a general logistic regression, and multilevel model to account for country level variations. Although there is minimal difference in the estimates of the determinants between the two models, the test for goodness of fit indicate that the multilevel model is superior (better fit) relative to the logistic regression model.

The results indicate that differences between counties accounted for $35.9 \%$ of the total variance in inpatient services unmet need, compared to $9.1 \%$ in outpatient services unmet need. Furthermore, a wide variation is reported in per capita spending on inpatient care by county [23]. This corroborates previous evidence that there exist inequities within the counties, and that Kenyans living in the same region could have different lifestyles and access to services [51]. Conversely, other studies have highlighted wider socio-economic and geographic inequities for inpatient care than outpatient care in Kenya [52]. However, there are likely to be more similarities among people within the same county in relation to cost-related unmet need for inpatient services relative to outpatient services. Contextual factors at the county level are likely to influence the individual factors on cost-related unmet need. For instance the degree of urbanity at county level, bearing in mind some counties are more urbanised than others and the rural urban disparities in Kenya [53]. This is consistent with studies elsewhere [54], moreover this study also noted a positive significant association between urban residence and cost-related unmet need. This confirms that place(region) does influence health seeking behaviour, like in this case of unmet need due to cost $[55,56]$.

The results show the positive and negative factors that influence cost-related unmet need controlling for county level variations. Age of household head increased the likelihood of cost-related unmet need for healthcare. This is possibly because older heads are reported to utilize alternative services like self-medication and traditional care [57]. An older age of the head of the household has been reported to increase health care spending [58], resulting in unmet need for care due to high costs. This is in accordance with inequalities in health status that younger people are in general healthier than older people [59]. Furthermore, some studies have shown that households headed by older people are more likely to experience higher health financial burden [14].

Households with an educated head were less likely to forgo care due to cost. Furthermore, lack of formal education is seen as a predictor of poverty given education opens up a range of income-generating opportunities [60]. Other studies have also reported lower levels of education increases the odds of having unmet need [61]. 
As expected, the need for inpatient services was associated with a higher risk of cost-related unmet need for care relative to outpatient services. This is because inpatient services are required for more severe illnesses [62], hence demanding high costs of care. Moreover, people may have spent more money for consultation prior to needing inpatient services hence depleted their only savings. Compared with other countries in the region (Ghana, Uganda, Zambia), Kenya is reported to have the highest average cost per inpatient bed- day, at about (\$41) per day [63], which hinder more people from utilizing the services.

Good self-rated health was associated with a less likelihood of unmet need for healthcare due to cost. This is consistent with other studies that report those with fair, good or very good self-reported health have a lower likelihood of foregone care, which decreases with better health status [64]. People with poor self-rated health are reported to frequent use of medical services [65]. Consistent with other studies, those from insured households had decreased odds of unmet need for care due to costs relative to uninsured households. Social healthcare insurance is reported to significantly reduce foregone care in outpatient and inpatient situations [64]. Elsewhere, financial risk protection through insurance is reported to minimize the prevalence of unmet need due to cost [66].

The larger the household, the less likely they are to forgo care due to cost this is perhaps due to reported pooling of resources among the many members [67] which is common in the African context. Despite the analysis showing more rural households (70.3\%) compared to urban households had cost-related unmet need for care, urban households had a positive association with cost-related unmet need. This is corroborated in another study in Kenya that established that forgone care is more heavily concentrated in urban areas [68] especially within the lowest income quintile. Furthermore in Kenya, rural households are reported to have significantly lower OOPs per capita compared to urban households [52]. There is also greater use of expensive health services, and higher costs charged in urban areas relative to rural areas [25]. Additionally, a significant proportion of urban residents (60 to 80\%) in Kenya live in informal settlements where a substantial proportion face $\mathrm{CHE}$, and are likely to forgo needed health care because they cannot afford [69]. In many cases, urban households are seen to spend more on OOP for healthcare than rural households, in absolute terms [70]. Consistent with another study in Kenya that foregone care was related to some extent to the available financial resources in a household [71], our findings show a negative association between household wealth and cost-related unmet need. Economic issues are reported to be the primary reason for not seeking healthcare [72]. Elsewhere, studies have shown that unmet needs for health care due to cost are consistently higher among people in low income groups compared with those in high income groups [73, 74]. This implies that wealthy households are less likely to forgo care due to cost, given when prices are high, the poor are more likely than the non-poor to forgo health services [50].

There are limitations to this study that need to be taken into account while interpreting the findings. First, we use the study population as those who reported to have been ill in the 4 weeks preceding the survey and/or needed to be admitted in the past 1 year. There could be differences in the ability of respondents to report illness or interpret illness differently across population groups. For instance, some people only report serious illness and not what they perceive as "less" serious. Second, the outpatient services focus on only the 4 weeks preceding the survey which could fail to capture some segments of the population given the time of fielding the study. This is because some leading causes of illnesses like Malaria are seasonal, that is they are prevalent at particular times of the year and in certain regions. Third, our analysis is based on a subjective unmet need assessment, i.e. the individuals' self-reported reasons for not seeking care. Previous evidence suggests that perception of health status varies by individual characteristics in that some individuals are better able to estimate their health and their health care needs than others. This study relies on the assumption that the response provided by the respondent was the main reason why care was not sought when needed, and hence could be biased because of the subjective interpretation.

\section{Conclusions}

Controlling for the county level significantly improved the model relative to fitting the general logistic regression. An important note we draw from fitting the multilevel model is the existence of disparities in cost-related unmet need between and within the counties. It is further evident that there exists variation across the regions that could be substantial in explaining the effect of the individual factors on cost-related unmet need. This implies that regional differences are important in explaining health access due to cost, furthermore the counties have varying socio-economic profiles that could predispose the populations to certain health seeking behaviour. The fact that inpatient services was associated with a higher likelihood of cost-related unmet need, highlights the nuances in measuring OOP payments. This shows that OOP for inpatient services as a fraction of household budget could be underestimated as many people may not seek the services due to cost barriers. 
The study underscores that affordability is a serious issue in access to healthcare services. The findings suggest that there are multiple factors that drive unmet need of healthcare services due to cost. This requires a multifaceted approach to addressing inequities in unmet need for care, especially among the most vulnerable and marginalised populations. For instance, under the 2010 constitution Kenya setup an 'equalization fund' to address unequal distribution of resources with counties as the unit of distribution. The equalization fund employs a county development index to allocate the funds using four parameters namely; poverty, infrastructure, health and education, to measure need. However, the indicators used to measure access to health are specific to certain services that is maternal health, immunization, and sanitation. This study emphasizes the need to reconsider access to health indicators in computing the county development index, to include overall access to healthcare services thus ensure 'fair' distribution of resources and address access barriers across the counties.

Health insurance is seen to lower the likelihood of cost-related unmet need, stressing that providing health insurance to the uninsured is key to enabling access. Scaling up of the social health insurance scheme would fundamentally require further segmentation of the population for better targeting, and to ensure it is tailored to match the needs of the various population segments. The current social health insurance scheme is based on a voluntary mechanism which disadvantages the nonemployed and poorest given they cannot afford the 'blanket' \$60 annual premiums. This calls for the need to consider significant improvements to the current insurance package by possibly subsidising premiums or giving exemptions for the most vulnerable and the poorest to improve equity in access.

\section{Supplementary information}

Supplementary information accompanies this paper at https://doi.org/10. 1186/s12913-020-05189-3.

Additional file 1. Distribution of cost-related unmet need and other reasons for unmet need for healthcare across the counties (regions).

Additional file 2. Distribution of the individuals with cost-related unmet need by socio-economic characteristics.

Additional file 3. Multilevel and logistic regression models.

\section{Abbreviations}

OOP: Out of Pocket; CHE: Catastrophic Health Expenditure; UHC: Universal Health Coverage; KHHEUS: Kenya household health expenditure and utilization Survey; ICC: Intraclass Correlation Coefficient; AIC: Alkaike's information Criterion; BIC: Bayesian Information Criterion

\section{Authors' contributions}

PN designed the research method, conducted the analysis, summarized the findings and discussions, constructed the figures and tables and prepared the manuscript. WG and JA provided inputs into the research method, structure of the manuscript, data analysis and findings, and reviewed all the draft versions of the manuscript. All the authors read and approved the final manuscript.

\section{Authors' information}

PN is a PhD Fellow at the United Nations University - MERIT, School of Governance, Maastricht University, The Netherlands.

\section{Funding}

No financial support was received.

\section{Availability of data and materials}

The datasets generated and/or analysed during the current study are available in the Kenya National Data Archive (KeNADA) repository http:// statistics.knbs.or.ke/nada/index.php/home, upon request.

Ethics approval and consent to participate

Not applicable.

\section{Consent for publication}

Not applicable.

\section{Competing interests}

The authors declare that they have no competing interests.

\section{Author details}

${ }^{1}$ United Nations University-MERIT, Maastricht Graduate School of Governance, Maastricht University, Maastricht, The Netherlands. ${ }^{2}$ Utrecht University School of Governance, Faculty of Law, Economics and Governance, Utrecht University, Utrecht, the Netherlands. ${ }^{3}$ Department of Health Services Research, Faculty of Health Medicine and Life Sciences, Maastricht University, Maastricht, The Netherlands.

Received: 19 July 2019 Accepted: 6 April 2020

Published online: 17 April 2020

\section{References}

1. Chen J, Rizzo JA, Rodriguez HP. The health effects of cost-related treatment delays. Am J Med Qual. 2011;26:261-71. https://doi.org/10.1177/ 1062860610390352

2. WHO, World Bank. Tracking universal health coverage : 2017 global monitoring report. The World Bank; 2017. http://documents.worldbank.org/ curated/en/640121513095868125/Tracking-universal-health-coverage-2017global-monitoring-report. Accessed 3 Dec 2018.

3. O'Donnell O. Access to health care in developing countries: breaking down demand side barriers. Cad Saúde Pública 2007;23:2820-2834. http://www. scielo.br/scielo.php?pid=S0102-311X2007001200003\&script=sci_arttext. Accessed 3 Jul 2016

4. Jacobs B, Ir P, Bigdeli M, Annear PL, Van Damme W. Addressing access barriers to health services: an analytical framework for selecting appropriate interventions in low-income Asian countries. Health Policy Plan. 2012;27: 288-300. https://doi.org/10.1093/heapol/czr038.

5. Gulliford M, Morgan M, editors. Access to health care. New York: Routledge; 2003.

6. OECD. Health at a glance 2011: OECD Publishing; 2011. https://doi.org/10. 1787/health_glance-2011-en.

7. Fiorillo D. Reasons for unmet needs for health care: the role of social capital and social support in some western EU countries. Int J Health Econ Manag. 2019. https://doi.org/10.1007/s10754-019-09271-0.

8. Fjær EL, Stornes PG, Borisova L, McNamara CL, Eikemo TA. Subjective perceptions of unmet need for health care in Europe among social groups: Findings from the European social survey (2014) special module on the social determinants of health; 2017. p. 82-9. https://doi.org/10.1093/eurpub/ ckw219.

9. Allin S, Grignon M, Le Grand J. Subjective unmet need and utilization of health care services in Canada: what are the equity implications? Soc Sci Med. 2010;70:465-72. https://doi.org/10.1016/j.socscimed.2009.10.027.

10. Allin S, Masseria C. Unmet need as an indicator of access to health care in Europe; 2009.

11. Allin S, Masseria C. Unmet need as an indicator of health care access. Eurohealth. 2009;15. 
12. Boerma JT. Tracking universal health coverage: first global monitoring report. 2015. http://apps.who.int/iris/bitstream/10665/174536/1/9789241564 977_eng.pdf?ua=1. Accessed 9 Dec 2018.

13. Swe KT, MdM R, MdS R, Saito E, Abe SK, Gilmour S, et al. Cost and economic burden of illness over 15 years in Nepal: A comparative analysis. PLOS ONE. 2018;13, e0194564. https://doi.org/10.1371/journal.pone.0194564.

14. Xu K, Evans DB, Kawabata K, Zeramdini R, Klavus J, Murray CJ. Household catastrophic health expenditure: a multicountry analysis. Lancet. 2003;362: 111-7. https://doi.org/10.1016/S0140-6736(03)13861-5.

15. Mchenga M, Chirwa GC, Chiwaula LS. Impoverishing effects of catastrophic health expenditures in Malawi. Int J Equity Health. 2017;16. https://doi.org/ 10.1186/s12939-017-0515-0.

16. Ezat Wan Puteh S, Almualm Y. Catastrophic Health Expenditure among Developing Countries. Health Syst Policy Res. 2017;04. https://doi.org/10. 21767/2254-9137.100069.

17. Wagstaff A, Flores G, Hsu J, Smitz M-F, Chepynoga K, Buisman LR, et al. Progress on catastrophic health spending in 133 countries: a retrospective observational study. Lancet Glob Health. 2018;6:e169-79. https://doi.org/10. 1016/S2214-109X(17)30429-1.

18. Nyanjom O. Inequality in Kenya's health sector. In: In Society for international development; 2006. p. 156.

19. Ndavi PM, Ogola S, Kizito PM, Johnson K. Decentralizing Kenya's health management system: an evaluation. Kenya working papers no. 1. Calverton, Maryland: Macro International Inc; 2009. https://dhsprogram.com/pubs/pdf/ WPK1/WPK1.pdf.

20. ODI. Leaving no one behind in the health sector. An SDG stocktake in Kenya and Nepal. Overseas Development Institute; 2016.

21. Mugo P, Onsomu E, Munga B, Mbithi J, Owino E. An Assessment of Healthcare Delivery in Kenya under the Devolved System. KIPPRA. 2018; Special Paper No. 19/2018:146.

22. Jivetti B, Alcántara AN, Miller JA, Rhatigan R. Financing health care in kenya: are kenyans willing to pay higher taxes for better health care? vol. 30; 2018.

23. MOH. 2013 Kenya household health Expenditureand UtilisationSurvey. Government of Kenya; 2014.

24. CRA. Kenya country fact sheets. Commission on revenue allocation; 2011. http://siteresources.worldbank.org/INTAFRICA/Resources/257994-133547195 9878/Kenya_County_Fact_Sheets_Dec 2011.pdf.

25. Chuma J, Gilson L, Molyneux C. Treatment-seeking behaviour, cost burdens and coping strategies among rural and urban households in coastal Kenya: an equity analysis. Tropical Med Int Health. 2007;12:673-86. https://doi.org/ 10.1111/j.1365-3156.2007.01825.x.

26. Berry KM, Parker W, Mchiza ZJ, Sewpaul R, Labadarios D, Rosen S, et al. Quantifying unmet need for hypertension care in South Africa through a care cascade: evidence from the SANHANES, 2011-2012. BMJ Glob Health. 2017;2:e000348. https://doi.org/10.1136/bmjgh-2017-000348.

27. Ayanore MA, Pavlova M, Groot W. Unmet reproductive health needs among women in some west African countries: a systematic review of outcome measures and determinants. Reprod Health. 2016;13:5. https://doi.org/10. 1186/s12978-015-0104-X.

28. Ettarh RR. Spatial analysis of contraceptive use and unmet need in Kenya; 2011.

29. Guure C, Maya ET, Dery S, Da-Costa Vrom B, Rm A, Hr R, et al. Factors influencing unmet need for family planning among Ghanaian married/ union women: a multinomial mixed effects logistic regression modelling approach. Arch Public Health. 2019;77:11. https://doi.org/10.1186/s13690019-0340-6.

30. Machiyama K, Cleland J. Insights into unmet need in Kenya. STEP UP Research Report. London School of Hygiene \& Tropical Medicine; 2013.

31. Muhammed KA, Umeh KN, Nasir SM, Suleiman IH. Understanding the barriers to the utilization of primary health care in a low-income setting: implications for health policy and planning. J Public Health Afr. 2013:e13. https://doi.org/10.4081/jphia.2013.e13.

32. Tey N-P, Lai S. Correlates of and barriers to the utilization of health Services for Delivery in South Asia and sub-Saharan Africa. Sci World J. 2013;2013:111. https://doi.org/10.1155/2013/423403.

33. Subramanian SV, Kawachi I, Kennedy BP. Does the state you live in make a difference? Multilevel analysis of self-rated health in the US. Soc Sci Med. 2001;53:9-19. https://doi.org/10.1016/S0277-9536(00)00309-9.

34. Allin S, Masseria C. Research Note: Unmet need as an indicator of access to health care in Europe, vol. 21; 2009
35. Academy of Medical Sciences. Unmet need in healthcare Summary of a roundtable held at the Academy of Medical Sciences on 31 July 2017, held with support from the British Academy and NHS England. The Academy of Medical Sciences; 2017.

36. Fjær EL, Stornes P, Borisova LV, McNamara CL, Eikemo TA. Subjective perceptions of unmet need for health care in Europe among social groups: Findings from the European social survey (2014) special module on the social determinants of health. Eur J Public Health. 2017;27(suppl_1):82-9. https://doi.org/10.1093/eurpub/ckw219.

37. Andersen RM, McCutcheon A, Aday LA, Chiu GY, Bell R. Exploring dimensions of access to medical care. Health Serv Res. 1983;18:49-74 https://www.ncbi.nlm.nih.gov/pmc/articles/PMC1068709/. Accessed 6 Dec 2018.

38. Babitsch B, Gohl D, von Lengerke T. Re-revisiting Andersen's behavioral model of health services use: a systematic review of studies from 19982011. GMS Psycho-Soc-Med. 2012;9. https://doi.org/10.3205/psm000089.

39. Diez-Roux AV. Multilevel analysis in public Health Research. Annu Rev Public Health. 2000;21:171-92. https://doi.org/10.1146/annurev.publhealth.21.1.171.

40. Roux AVD. Next steps in understanding the multilevel determinants of health. J Epidemiol Community Health. 2008;62:957. https://doi.org/10.1136/ jech.2007.064311.

41. Sommet N, Morselli D. Keep calm and learn multilevel logistic modeling: a simplified three-step procedure using Stata, R, Mplus, and SPSS. Int Rev Soc Psychol. 2017;30:203-18. https://doi.org/10.5334/irsp.90.

42. Park S, Lake ET. Multilevel modeling of a clustered continuous outcome. Nurs Res. 2005;54:406-13 https://www.ncbi.nlm.nih.gov/pmc/articles/ PMC1540459/. Accessed 8 Jun 2019.

43. Burnham KP, Anderson DR. Multimodel inference: understanding AIC and BIC in model selection. Sociol Methods Res. 2004;33:261-304. https://doi. org/10.1177/0049124104268644.

44. Ngugi AK, Agoi F, Mahoney MR, Lakhani A, Mang'ong'o D, Nderitu E, et al. Utilization of health services in a resource-limited rural area in Kenya: prevalence and associated household-level factors. PLoS One. 2017;12: e0172728.

45. Cavalieri M. Geographical variation of unmet medical needs in Italy: a multivariate logistic regression analysis. Int J Health Geogr. 2013;12:27. https://doi.org/10.1186/1476-072X-12-27.

46. Popovic N, Terzic-Supic Z, Simic S, Mladenovic B. Predictors of unmet health care needs in Serbia; Analysis based on EU-SILC data. PLOS ONE. 2017;12: e0187866. https://doi.org/10.1371/journal.pone.0187866.

47. Ganesh L. Impact of indirect cost on access to healthcare utilization. Int J Med Sci Public Health. 2015;4:1255. https://doi.org/10.5455/ijmsph.2015. 28012015258

48. Chuma J, Maina T. Catastrophic health care spending and impoverishment in Kenya. BMC Health Serv Res. 2012;12:413.

49. Achoki T, Miller-Petrie MK, Glenn SD, Kalra N, Lesego A, Gathecha GK, et al. Health disparities across the counties of Kenya and implications for policy makers, 1990-2016: a systematic analysis for the global burden of disease study 2016. Lancet Glob Health. 2019;7:e81-95. https://doi.org/10.1016/ S2214-109X(18)30472-8.

50. Castro-Leal F, Dayton J, Demery L, Mehra K. Public spending on health care in Africa: do the poor benefit. Inequalities Health. 2000;:9.

51. KNBS SID. Exploring Kenya's inequality: pulling apart or pooling together? 2013.

52. Chuma J, Okungu V. Viewing the Kenyan health system through an equity lens: implications for universal coverage. Int J Equity Health. 2011;10:22. https://doi.org/10.1186/1475-9276-10-22.

53. Stiftung F-E. Regional disparities and marginalisation in Kenya. FriedrichEbert-Stiftung; 2012

54. Lee SE, Yeon M, Kim C-W, Yoon T-H. The association among individual and contextual factors and unmet healthcare needs in South Korea: a multilevel study using National Data. J Prev Med Pub Health. 2016;49:308-22. https:// doi.org/10.3961/jpmph.16.035.

55. Duncan C, Jones K, Moon G. Special issue the scope of medical GeographyDo places matter? A multi-level analysis of regional variations in health-related behaviour in Britain. Soc Sci Med. 1993;37:725-33. https://doi. org/10.1016/0277-9536(93)90366-C.

56. Vedom J, Cao H. Health care access and regional disparities in China. Space, Population and Societies. 2011. http://citeseerx.ist.psu.edu/viewdoc/ download?doi=10.1.1.900.550\&rep=rep1\&type=pdf. 
57. Omonona BT, Obisesan AA, Aromolaran OA. Health-care access and utilization among rural households in Nigeria. J Dev Agric Econ. 2015;7:195203. https://doi.org/10.5897/JDAE2014.0620.

58. Kwakye E. Household Health Care Expenditure and Catastrophic Payments: Evidence From The Ghana Living Standards Survey V, vol. 22; 2017.

59. McMurdo MET. A healthy old age: realistic or futile goal? BMJ. 2000;321: 1149-1151. https://www.ncbi.nlm.nih.gov/pmc/articles/PMC1118909/. Accessed 3 Jul 2019.

60. Awiti JO. Poverty and health care demand in Kenya. BMC Health Serv Res. 2014;14. https://doi.org/10.1186/s12913-014-0560-y.

61. Kim J, Kim TH, Park E-C, Cho WH. Factors influencing unmet need for health Care Services in Korea. Asia Pac J Public Health. 2015;27:NP2555-69.

62. Atake $\mathrm{E}-\mathrm{H}$, Amendah DD. Porous safety net: catastrophic health expenditure and its determinants among insured households in Togo. BMC Health Serv Res. 2018;18. https://doi.org/10.1186/s12913-018-2974-4.

63. HHME. Health Service Provision in Kenya: Assessing Facility Capacity, Costs of Care, and Patient Perspectives, vol. 78. Seattle WA: Inst Health Metr Eval; 2014

64. Li X, Chen M, Wang Z, Si L. Forgone care among middle aged and elderly with chronic diseases in China: evidence from the China health and retirement longitudinal study baseline survey. BMJ Open. 2018;8:e019901. https://doi.org/10.1136/bmjopen-2017-019901.

65. Isaac V, McLachlan CS, Baune BT, Huang C-T, Wu C-Y. Poor Self-Rated Health Influences Hospital Service Use in Hospitalized Inpatients With Chronic Conditions in Taiwan. Medicine (Baltimore). 2015;94:e1477. https://doi.org/ 10.1097/MD.0000000000001477.

66. Thammatacharee N, Tisayaticom K, Suphanchaimat R, Limwattananon S, Putthasri W, Netsaengtip R, et al. Prevalence and profiles of unmet healthcare need in Thailand. BMC Public Health. 2012;12. https://doi.org/10. 1186/1471-2458-12-923.

67. Njagi P, Arsenijevic J, Groot W. Understanding variations in catastrophic health expenditure, its underlying determinants and impoverishment in sub-Saharan African countries: a scoping review. Syst Rev. 2018;7:136. https://doi.org/10.1186/s13643-018-0799-1

68. Zollmann J, Ravishankar N. Struggling to thrive: How Kenya's low-income families (try to) pay for healthcare, vol. 40; 2016.

69. Buigut S, Ettarh R, Amendah DD. Catastrophic health expenditure and its determinants in Kenya slum communities. Int J Equity Health. 2015;14. https://doi.org/10.1186/s12939-015-0168-9.

70. Wang L, Wang A, Zhou D, FitzGerald G, Ye D, Jiang Q. An empirical analysis of rural-urban differences in out-of-pocket health expenditures in a lowincome Society of China. PLoS One. 2016;11. https://doi.org/10.1371/journal. pone.0154563.

71. Bonfrer I, Gustafsson-Wright E. Health shocks, coping strategies and foregone healthcare among agricultural households in Kenya. Glob Public Health. 2016:1-22. https://doi.org/10.1080/17441692.2015.1130847.

72. Ro YS, Shin SD, Jeong J, Kim MJ, Jung YH, Kamgno J, et al. Evaluation of demands, usage and unmet needs for emergency care in Yaounde, Cameroon: a cross-sectional study. Bmj Open. 2017;7:e014573.

73. OECD. Unmet needs for health care due to cost; 2017. https://doi.org/10. 1787/health_glance-2017-25-en.

74. Hwang J. Understanding reasons for unmet health care needs in Korea: what are health policy implications? BMC Health Serv Res. 2018;18:557. https://doi.org/10.1186/s12913-018-3369-2.

\section{Publisher's Note}

Springer Nature remains neutral with regard to jurisdictional claims in published maps and institutional affiliations.

Ready to submit your research? Choose BMC and benefit from:

- fast, convenient online submission

- thorough peer review by experienced researchers in your field

- rapid publication on acceptance

- support for research data, including large and complex data types

- gold Open Access which fosters wider collaboration and increased citations

- maximum visibility for your research: over $100 \mathrm{M}$ website views per year

At BMC, research is always in progress.

Learn more biomedcentral.com/submissions 